\title{
Survival after pulmonary rehabilitation in patients with COPD: impact of functional exercise capacity and its changes
}

This article was published in the following Dove Press journal:

International Journal of COPD

26 October 2016

Number of times this article has been viewed

\author{
Carlos A Camillo ${ }^{1,2}$ \\ Daniel Langer ${ }^{1,2}$ \\ Christian R Osadnik ${ }^{1,3-5}$ \\ Lisa Pancini ${ }^{2}$ \\ Heleen Demeyer ${ }^{1,2}$ \\ Chris Burtin ${ }^{1,6}$ \\ Rik Gosselink ${ }^{1,2}$ \\ Marc Decramer ${ }^{2}$ \\ Wim Janssens ${ }^{2}$ \\ Thierry Troosters ${ }^{1,2}$ \\ 'KU Leuven, Department of \\ Rehabilitation Sciences, Leuven, \\ Belgium; ${ }^{2}$ University Hospital \\ Leuven, Respiratory Division and \\ Rehabilitation, Leuven, Belgium; \\ ${ }^{3}$ Monash University, Department \\ of Physiotherapy, Melbourne, VIC, \\ Australia; ${ }^{4}$ Institute for Breathing \\ and Sleep, Melbourne, VIC, Australia; \\ ${ }^{5}$ Monash Health, Monash Lung and \\ Sleep, Melbourne, VIC, Australia; \\ ${ }^{6} \mathrm{Hasselt}$ University, Rehabilitation \\ Research Centre, Biomedical Research \\ Institute, Faculty of Medicine and Life \\ Sciences, Diepenbeek, Belgium
}

Correspondence: Thierry Troosters University Hospital Leuven, Respiratory Division and Rehabilitation, UZ Gasthuisberg, Onderwijs en Navorsing I, Labo Pneumologie, Herestraat 49, Bus 706, B-3000, Leuven, Belgium

Tel +32 I6 330798

Fax +3216330805

Email thierry.troosters@kuleuven.be
Abstract: The impact of rehabilitation-induced changes in 6-minute walk distance (6MWD) on the survival of patients with chronic obstructive pulmonary disease (COPD) has not been fully elucidated. This study sought to determine the association of baseline 6MWD and its changes after pulmonary rehabilitation (PR) with 5-year survival in patients with COPD. Patients who were referred to a 12-week outpatient PR program were followed up for 5 years postcompletion, and survival status was verified. Survival was analyzed according to four groups based upon initial 6MWD (6MWDi) and its changes ( $\triangle 6 \mathrm{MWD}$ ) after PR (Group 1: 6MWDi $\geq 350 \mathrm{~m}$ and $\Delta 6 \mathrm{MWD} \geq 30 \mathrm{~m}$; Group 2: 6MWDi $\geq 350 \mathrm{~m}$ and $\Delta 6 \mathrm{MWD}<30 \mathrm{~m}$; Group 3: 6MWDi $<350 \mathrm{~m}$ and $\Delta 6 \mathrm{MWD} \geq 30 \mathrm{~m}$; and Group 4: $6 \mathrm{MWDi}<350 \mathrm{~m}$ and $\Delta 6 \mathrm{MWD}<30 \mathrm{~m}$ ) via Kaplan-Meier analysis and log rank test. Cox regression was performed to identify possible confounders of mortality estimates. In total, 423 patients (with mean \pm standard deviation of forced expiratory volume in the first second $\left[\mathrm{FEV}_{1}\right] 43 \pm 16 \%$ predicted, age $65 \pm 8$ years, and 6WMDi $381 \pm 134 \mathrm{~m}$ ) underwent PR between 1999 and 2010. Survival rates decreased progressively from Group 1 to Group 4 (Group 1, 81\%; Group 2, 69\%; Group 3, 47\%; Group 4, 27\%; log rank test, $P<0.05$ ). 6MWDi $\geq 350 \mathrm{~m}$ (hazard ratio [HR] 0.39 [95\% confidence interval $\{\mathrm{CI}\} 0.30-0.50]$ ) and $\Delta 6 \mathrm{MWD} \geq 30 \mathrm{~m}$ (HR 0.66 [95\% CI 0.51-0.85]) were strongly and independently associated with survival. Compared with Group 1, mortality risks progressively increased in Group 2 (HR 1.36 [95\% CI 0.92-2.00]; not significant), Group 3 (HR 1.90 [95\% CI 1.28-2.84]; $P=0.001$ ), and Group 4 (HR 3.28 [95\% CI 2.02-5.33]; $P<0.0001$ ). Both poor 6MWD and lack of improvement $>30 \mathrm{~m}$ after PR are associated with worse 5-year survival in patients with COPD.

Keywords: pulmonary disease, chronic obstructive, exercise training, mortality, 6-minute walk test, minimally important difference

\section{Introduction}

The 6-minute walk test (6MWT) is one of the most widely used assessments of exercise performance in chronic obstructive pulmonary disease (COPD), and a distance covered during the test (6-minute walk distance [6MWD]) is considered the primary test outcome. ${ }^{1}$ A considerable body of evidence demonstrates the importance of this test in clinical practice. Low 6MWD has consistently been associated with poor outcomes such as higher risks of respiratory and all-cause mortality in patients with COPD. ${ }^{2}$ It has been shown that patients who walk less than $350 \mathrm{~m}$ have a high risk of mortality. ${ }^{3}$ Twenty years ago, Gerardi et al reported that the distance covered in a 12MWT after exercise training is the strongest mortality predictor in patients with COPD. ${ }^{4}$ Increases in exercise capacity have also been demonstrated to improve the likelihood of 6-year 
survival in patients with other diseases. ${ }^{5}$ To date, less is known about the impact of improved 6MWD on survival in respiratory patients.

Currently, pulmonary rehabilitation (PR) that includes high-intensity exercise training is the best strategy to improve exercise performance in patients with COPD ${ }^{6}$ In addition to the well-known impact of PR on a wide range of outcomes (eg, exercise capacity, muscle force, health-related quality of life, and symptoms), PR has demonstrated some positive effects on the risk of hospitalisation ${ }^{7}$ and indirect association with mortality by comparing the survival of completers with that of patients who declined or did not complete the intervention in the following 4 years. ${ }^{8}$

There is compelling evidence demonstrating that an increase in 6MWD of $30 \mathrm{~m}$ is clinically important. ${ }^{1,2}$ This improvement is typically achieved with PR; ${ }^{9}$ however, not all the patients benefit to the same extent. ${ }^{10}$ It is unclear whether an interaction exists between lack of improvements in 6MWD and poor survival after PR. Outside the context of PR, deterioration of $6 \mathrm{MWD}>30 \mathrm{~m}$ over 1 year has been shown to increase the risk of hospitalizations and mortality. ${ }^{11}$ This further supports the use of this threshold in clinical practice.

The present study aimed to investigate the associations of 6MWD before PR and changes in 6MWD after PR with 5-year survival in patients with COPD.

\section{Methods}

\section{Patients}

Patients diagnosed with $\mathrm{COPD}^{12}$ and referred to the outpatient PR program of the University Hospital Leuven between 1999 and 2010 were included in this retrospective study. Ethical approval was obtained from the hospital committee (S58488). The medical ethics committee of the University Hospital Leuven did not require informed consent to be obtained for this study, as it is seldom possible to obtain retrospective consents in studies investigating survival. Multiple diagnoses were allowed unless deemed to potentially preclude training completion or significantly affect prognosis (eg, awaiting lung transplantation, lung cancer). Patients who did not provide complete data regarding baseline 6MWD and/or 60-month survival status were excluded from the study. In order to investigate the effects on mortality of both initial 6MWD (6MWDi) and its change $(\triangle 6 \mathrm{MWD})$ after PR, patients were classified into one of four groups, defined a priori (Group 1: 6MWDi $\geq 350 \mathrm{~m}$ and $\triangle 6 \mathrm{MWD} \geq 30 \mathrm{~m}$; Group 2: $6 \mathrm{MWDi} \geq 350$ $\mathrm{m}$ and $\triangle 6 \mathrm{MWD}<30 \mathrm{~m}$; Group 3: $6 \mathrm{MWDi}<350 \mathrm{~m}$ and $\triangle 6 \mathrm{MWD} \geq 30 \mathrm{~m}$; and Group 4: 6MWDi $<350 \mathrm{~m}$ and $\Delta 6 \mathrm{MWD}<30 \mathrm{~m}$ ). The $350-\mathrm{m}$ cutoff was chosen in this study as this has previously been shown to provide the best combination of sensitivity and specificity to detect mortality in patients with $\mathrm{COPD},{ }^{3}$ whereas the $30-\mathrm{m}$ change cutoff represents the accepted minimally important difference for the 6MWT. ${ }^{1}$ Patients who failed to complete 3 months of training (dropouts) were considered nonresponders and included in Group 2 or 4, according to their 6MWDi.

\section{Assessments}

Before and after PR, all patients underwent routine screening that included complete lung function test, ${ }^{13}$ incremental cardiopulmonary cycling test, ${ }^{14,15}$ two 6MWTs (the highest distance covered), ${ }^{1}$ muscle force (dynamometry), and health-related quality of life (chronic respiratory disease questionnaire). ${ }^{16}$ Comorbidities were identified by using documented medication use at the initial assessment and were classified into four categories: cardiovascular, metabolic, musculoskeletal, and mental health. Medical records were inspected following PR completion to determine the timing and incidence of a first hospitalization.

\section{PR program}

All the patients participated in a comprehensive, interdisciplinary, 6-month PR program that included social, nutritional, and psychological support; optimization of prescription medications; and exercise training. The program was divided into two parts of equal duration (Months 1-3: intensive program; Months 4-6: maintenance program). The intensive program comprised of three sessions per week of high-intensity aerobic and resistive exercises for both the lower and upper limbs. Upon completion, patients were encouraged to continue for a further 3 months at a reduced frequency (two sessions per week) where training intensity and duration were not progressed further ${ }^{17}$ (ie, maintenance). Data from our center has shown the vast majority of training benefits typically occur during the initial intensive program. ${ }^{18}$ Therefore, for comparability with many other PR programs, PR responses relative to the initial 3-month period are reported. Further information regarding characteristics and effectiveness of this PR program has been described in some previous studies..$^{10,19}$

\section{Survival status}

Survival status was determined at 60 months after PR completion by the inspection of electronic PR databases and hospital medical records. At our center in Leuven, patients underwent annual review with a maximal permitted variation of 6 months. Therefore, any hospital visit (eg, outpatient appointment and admission) between Months 54 and 60 was deemed indicative of 60 months of survival. If the status could not be verified, electronic obituary records 
were examined. If no conclusive information was obtained, vital status was checked by contacting the patient's general practitioner or relative. Patients with unclear survival status after this stage were excluded from the study.

\section{Statistical analysis}

A complete description of the statistical analysis is provided in the Supplementary material. Statistical analysis was conducted by using SAS Version 9.3 (SAS Institute Inc., Cary, NC, USA). Mortality curves were plotted using survival estimates and were compared between groups by using log rank test and the Kaplan-Meier approach. A sensitivity analysis of potential confounders of mortality was conducted, which is further described in the Supplementary material. Cox regression analysis was used to adjust mortality estimates for potential confounders of survival (eg, age, quadriceps force, ${ }^{20}$ lung function, ${ }^{21}$ maximal exercise capacity, ${ }^{22}$ body mass index, ${ }^{23}$ and comorbidities ${ }^{24}$ ) and the additional impact of improved outcomes after PR (ie, cardiopulmonary exercise test, quadriceps force, health-related quality of life, and body mass index). Adjusted mortality estimates for Groups 2, 3 , and 4 were then compared to Group 1. Significance of mortality confounders was tested by using univariate regression analysis, and then, a multivariate model was used if statistically significant. Individually adjusted risks of mortality were estimated by calculating hazard ratios. Statistical significance was denoted by $P<0.05$.

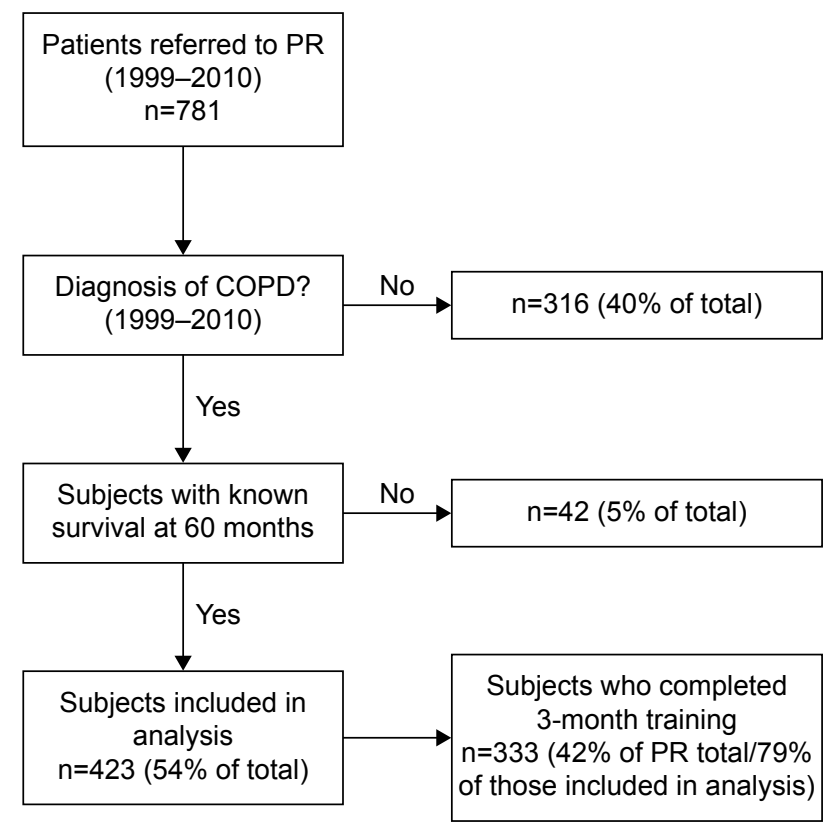

Figure I Flow chart of patients' inclusion.

Abbreviations: COPD, chronic obstructive pulmonary disease; PR, pulmonary rehabilitation.

\section{Results}

Figure 1 demonstrates the flowchart of patients' inclusion in the present study. In total, 423 COPD patients who were referred to PR with known survival status at 60 months were included. Most of them $(n=333,78 \%)$ completed at least 3 months of PR. Table 1 describes the baseline characteristics of the patients. Differences in exercise capacity (ie, 6MWD and cardiopulmonary cycling test) and muscle force were observed between patients who did or did not complete 3 months of training $(P<0.01)$. Significantly better baseline lung function $(P<0.001)$, muscle force $(P<0.01)$, exercise capacity (6MWD and cardiopulmonary cycling test; $P<0.001)$, and healthrelated quality of life $(P<0.01)$ were observed for patients with better baseline 6MWD (Groups 1 and 2) compared to patients with low baseline 6MWD (Groups 3 and 4).

\section{Rehabilitation responses}

Significant positive effects were observed on measures of muscle force $(11 \pm 18 \mathrm{Nm}), 6 \mathrm{MWD}(45 \pm 73 \mathrm{~m})$, incremental cycling test ( $10 \pm 15$ watts), and health-related quality of life (chronic respiratory disease questionnaire, $16 \pm 12$ points) after 3 months of training in the entire cohort $(P<0.05$ for all). In total, 125 patients $(60 \%$ of those who completed 3 months of training) improved 6MWD $>30 \mathrm{~m}$, and 243 improved chronic respiratory disease questionnaire (total score) by the minimally important difference of $>10$ points. ${ }^{25}$ Differences in training effects were observed between the four groups (Table 2). By definition, Groups 2 and 4 had less improvement in 6MWD than Groups 1 and 3. Despite the lack of improvements in exercise tolerance, Groups 2 and 4 experienced clinical improvements in health-related quality of life $(P<0.01)$.

\section{Post-PR care}

The majority of patients $(83 \%$ of those who completed 3 months of training) followed the maintenance program during 3-6 months. The proportion of attendees was high in Group 1 (93\%) and Group 3 (84\%), compared with 79\% and $61 \%$ in Groups 2 and 4 , respectively $(P<0.001)$. A small proportion of attendees $(n=54,13 \%)$ were rereferred for a second course of PR at some point during the 60-month follow-up period. The incidence of having at least one respiratoryrelated hospitalization during the year after beginning PR was significantly different between patients who completed the training and those who did not complete and increased from Group 1 to Group 4 (26\%-56\%; Table $1 ; P<0.001)$.

\section{Mortality risk}

The Kaplan-Meier analysis revealed significant differences in survival trajectories between all four groups (log rank 
Table I Baseline characteristics of subjects

\begin{tabular}{|c|c|c|c|c|c|c|c|c|c|}
\hline \multirow[t]{3}{*}{ Demographic characteristics } & \multirow{3}{*}{$\begin{array}{l}\text { All } \\
\text { subjects }\end{array}$} & \multicolumn{3}{|c|}{ Completed 3 months of PR } & \multicolumn{4}{|c|}{ Groups according to $6 \mathrm{MWDi}$ and $\triangle 6 \mathrm{MWD}$} & \multirow[t]{3}{*}{$P$-value } \\
\hline & & \multirow[t]{2}{*}{ Yes } & \multirow[t]{2}{*}{ No } & \multirow[t]{2}{*}{$P$-value } & \multicolumn{2}{|c|}{$6 M W D i \geq 350 \mathrm{~m}$} & \multicolumn{2}{|c|}{ 6MWDi $<350 \mathrm{~m}$} & \\
\hline & & & & & $\begin{array}{l}\Delta \geq 30 \mathrm{~m} ; \\
\text { Group I }\end{array}$ & $\begin{array}{l}\Delta<30 \mathrm{~m} ; \\
\text { Group } 2\end{array}$ & $\begin{array}{l}\Delta \geq 30 \mathrm{~m} ; \\
\text { Group } 3\end{array}$ & $\begin{array}{l}\Delta<30 \mathrm{~m} ; \\
\text { Group } 4\end{array}$ & \\
\hline Number of patients & 423 & 333 & 90 & & 125 & 144 & 74 & 80 & \\
\hline Age (years) & $65 \pm 8$ & $66 \pm 8$ & $65 \pm 8$ & 0.7118 & $65 \pm 8$ & $65 \pm 8$ & $67 \pm 8$ & $67 \pm 8$ & 0.2380 \\
\hline Male sex, n (\%) & $335(79)$ & $265(80)$ & $70(78)$ & 0.7087 & $97(77)$ & $115(80)$ & $60(8 I)$ & $63(79)$ & 0.9400 \\
\hline BMI $\left(\mathrm{kg} \cdot \mathrm{m}^{-2}\right)$ & $25 \pm 6$ & $25 \pm 5$ & $25 \pm 7$ & 0.7913 & $26 \pm 5$ & $26 \pm 5$ & $24 \pm 6$ & $25 \pm 6$ & 0.5474 \\
\hline \multicolumn{10}{|l|}{ Lung function } \\
\hline $\mathrm{FEV}_{1}$ (\% predicted) & $43 \pm 16$ & $43 \pm 15$ & $44 \pm 19$ & 0.8367 & $46 \pm 16$ & $47 \pm 16$ & $37 \pm 12^{*, \dagger}$ & $37 \pm 16^{*, \dagger}$ & $<\mathbf{0 . 0 0 0 1}$ \\
\hline $\mathrm{FEV}_{1} / \mathrm{FVC}(\%)$ & $4 I \pm 12$ & $40 \pm 11$ & $43 \pm 15$ & 0.1643 & $42 \pm 11$ & $42 \pm 11$ & $37 \pm 1 I^{*,+}$ & $39 \pm 15$ & 0.0066 \\
\hline FRC (\% predicted) & $154 \pm 37$ & $154 \pm 37$ & $152 \pm 38$ & 0.5906 & $152 \pm 35$ & $150 \pm 34$ & $166 \pm 40 *, \dagger$ & $153 \pm 39$ & 0.0275 \\
\hline $\mathrm{DL}_{\mathrm{co}}(\%$ predicted $)$ & $48 \pm 17$ & $48 \pm 18$ & $48 \pm 18$ & 0.8556 & $53 \pm 17$ & $52 \pm 17$ & $4 I \pm 13^{*,+}$ & $40 \pm 17^{*, \dagger}$ & $<0.000$ I \\
\hline \multicolumn{10}{|l|}{ Peripheral muscle force } \\
\hline $\mathrm{QF}(\mathrm{Nm})$ & $100 \pm 38$ & $102 \pm 37$ & $92 \pm 38$ & 0.0232 & $113 \pm 35$ & $110 \pm 35$ & $79 \pm 30^{*, \dagger}$ & $80 \pm 35^{*, \dagger}$ & $<0.0001$ \\
\hline QF (\% predicted) & $69 \pm 26$ & $69 \pm 23$ & $66 \pm 36$ & 0.4644 & $75 \pm 21$ & $78 \pm 28$ & $57 \pm 23^{*, \dagger}$ & $58 \pm 25^{*, \dagger}$ & $<0.000$ I \\
\hline \multicolumn{10}{|l|}{ Exercise capacity } \\
\hline Oxygen uptake (\% predicted) & $48 \pm 19$ & $49 \pm 19$ & $44 \pm 18$ & 0.0245 & $53 \pm 18$ & $51 \pm 18$ & $40 \pm 18^{*, \dagger}$ & $42 \pm 2 I^{*, \dagger}$ & $<\mathbf{0 . 0 0 0 1}$ \\
\hline Oxygen uptake $\left(\mathrm{mL} \cdot \mathrm{kg} \cdot \mathrm{min}^{-1}\right)$ & $14 \pm 4$ & $14 \pm 4$ & $13 \pm 4 *$ & 0.0038 & $16 \pm 4$ & $15 \pm 5$ & $12 \pm 4^{*, \dagger}$ & $1 \mathrm{II} \pm 3^{*, \dagger}$ & $<\mathbf{0 . 0 0 0 1}$ \\
\hline Max workload (\% predicted) & $48 \pm 20$ & $49 \pm 19$ & $45 \pm 20$ & 0.0892 & $55 \pm 19$ & $53 \pm 18$ & $37 \pm 18^{*, \dagger}$ & $37 \pm 16^{*, \dagger}$ & $<0.000$ I \\
\hline 6MWD $(\mathrm{m})$ & $381 \pm 134$ & $395 \pm 129$ & $328 \pm 138$ & $<0.0001$ & $458 \pm 65$ & $469 \pm 74$ & $234 \pm 78^{*, \dagger}$ & $230 \pm 84^{*, \dagger}$ & $<0.0001$ \\
\hline 6MWD (\% predicted) & $59 \pm 21$ & $6 I \pm 20$ & $52 \pm 22$ & $<\mathbf{0 . 0 0 0 I}$ & $71 \pm 10$ & $73 \pm 11$ & $37 \pm 13^{*,+}$ & $37 \pm 14^{*, \dagger}$ & $<0.000$ I \\
\hline \multicolumn{10}{|l|}{ Health-related quality of life } \\
\hline CRDQ dyspnea (points) & $15 \pm 5$ & $16 \pm 5$ & $15 \pm 5$ & 0.4908 & $16 \pm 5$ & $16 \pm 5$ & $14 \pm 5^{*}$ & $15 \pm 5$ & 0.0161 \\
\hline CRDQ total score & $78 \pm 17$ & $78 \pm 17$ & $76 \pm 17$ & 0.1916 & $81 \pm 16$ & $79 \pm 17$ & $74 \pm 17^{*}$ & $73 \pm 16 *$ & 0.0026 \\
\hline \multicolumn{10}{|l|}{ Comorbidities } \\
\hline Cardiovascular (n, \%) & $313(74)$ & $246(74)$ & $67(75)$ & 0.8535 & $68(85)$ & $59(79)$ & $94(66)$ & $92(74)$ & 0.0124 \\
\hline Metabolic (n, \%) & $62(15)$ & $42(13)$ & $20(23)$ & 0.0209 & $12(10)$ & $17(12)$ & $14(19)$ & $19(24)$ & 0.0225 \\
\hline Musculoskeletal (n, \%) & $87(21)$ & 7I (22) & $16(18)$ & 0.4730 & $23(19)$ & $17(12)$ & $26(35)$ & $21(26)$ & 0.0005 \\
\hline Mental health $(\mathrm{n}, \%)$ & $125(30)$ & $94(28)$ & $31(35)$ & 0.2387 & $35(28)$ & $34(24)$ & $27(36)$ & $29(36)$ & 0.1299 \\
\hline \multicolumn{10}{|l|}{ Hospital admissions in the first year } \\
\hline $\begin{array}{l}\text { Time to first respiratory } \\
\text { hospitalization (days) }\end{array}$ & $129 \pm 97$ & $99 \pm 88$ & $138 \pm 99$ & 0.0280 & $176 \pm 97$ & $122 \pm 103$ & $128 \pm 89$ & $103 \pm 90 *$ & 0.0129 \\
\hline Hospitalizations within PR $(n, \%)$ & $72(17)$ & $49(14)$ & $23(25)$ & 0.0152 & $8(6)$ & $24(17)$ & $16(22)$ & $24(30)$ & 0.0001 \\
\hline $\begin{array}{l}\text { Hospitalizations in the } \\
\text { first year }(n, \%)\end{array}$ & $161(38)$ & $121(36)$ & $40(44)$ & 0.1598 & $32(25)$ & $48(33)$ & $36(48)$ & $45(56)$ & $<0.0001$ \\
\hline
\end{tabular}

Notes: Data shown as mean \pm SD, $\mathrm{n}(\%)$, or $P$-value. Group I: $6 \mathrm{MWDi} \geq 350 \mathrm{~m}$ and $\triangle 6 \mathrm{MWD} \geq 30 \mathrm{~m}$; Group 2: $6 \mathrm{MWDi} \geq 350 \mathrm{~m}$ and $\triangle 6 \mathrm{MWD}<30 \mathrm{~m}$; Group 3: 6MWDi $<350 \mathrm{~m}$ and $\triangle 6 \mathrm{MWD} \geq 30 \mathrm{~m}$; and Group 4:6MWDi $<350 \mathrm{~m}$ and $\triangle 6 \mathrm{MWD}<30 \mathrm{~m}$. P-values of the four groups refer to one-way analysis of variance or Kruskal-Wallis test; $* P<0.05$ in post hoc test versus $I$; ${ }^{\dagger} P<0.05$ in post hoc test versus 2 . Bold font denotes statistical significance $(P<0.05)$.

Abbreviations: 6MWD, 6-minute walk distance; 6MWDi, initial 6MWD; BMI, body mass index; CRDQ, chronic respiratory disease questionnaire; $D L_{c o}$, diffusion capacity for carbon monoxide; FEV , forced expiratory volume in the first second; FRC, functional residual capacity; FVC, forced vital capacity; max, maximum; PR, pulmonary rehabilitation; QF, quadriceps force; SD, standard deviation.

test, $P<0.05$ ), with survival rates progressively decreasing from Group 1 to Group 4 (Figure 2). The sensitivity analysis revealed no differences in responses attributable to the inclusion of dropouts in Groups 2 and 4 or between the periods during which the patients were referred to PR (1999-2004 or 2005-2010). Seven patients died ( $n=1$ in Group 2 and $n=6$ in Group 4) within the 3-month PR period. In the complete 60-month follow-up, Groups 1 and 2 demonstrated lower mortality rates (19\% and $31 \%$, respectively) compared to Groups 3 and 4 (53\% and 73\%, respectively).

Univariate regression analysis confirmed commonly described mortality predictors that are significant in this cohort (Table 3). All a priori defined confounders significantly predicted mortality $(P<0.001$ for all). The values $6 \mathrm{MWDi}$ and $\triangle 6 \mathrm{MWD} \geq 30 \mathrm{~m}$ after PR were strong predictors of mortality ( $P<0.01$ for both). Changes in other exercise outcomes after training significantly had an impact on mortality $(P<0.01$ for all).

Multivariate analysis revealed age, lung function, peak oxygen uptake, changes in quadriceps and cycling exercise outcomes, and both 6MWDi and $\triangle 6$ MWD (Table 3) to be significantly predictive of mortality. Relative to Group 1 (reference group), the risk of mortality at 60 months was significantly increased in all other groups (Table 4), increasing from 1.36 times higher in Group 2 to 3.28 times higher in Group 4 ( $P<0.05$ only for Groups 3 and 4$)$. 
Table 2 Exercise training responses

\begin{tabular}{|c|c|c|c|c|c|}
\hline \multirow[t]{2}{*}{ Outcomes } & \multirow{2}{*}{$\begin{array}{l}\text { All subjects } \\
(n=333)\end{array}$} & \multicolumn{2}{|c|}{$6 M W D i \geq 350 \mathrm{~m}$} & \multicolumn{2}{|c|}{ 6MWDi <350 m } \\
\hline & & $\begin{array}{l}\Delta \geq 30 \mathrm{~m} ; \\
\text { Group I } \\
(\mathrm{n}=125)\end{array}$ & $\begin{array}{l}\Delta<30 \mathrm{~m} ; \\
\text { Group } 2 \\
(\mathrm{n}=98)\end{array}$ & $\begin{array}{l}\Delta \geq 30 \mathrm{~m} ; \\
\text { Group } 3 \\
(\mathrm{n}=74)\end{array}$ & $\begin{array}{l}\Delta<30 \mathrm{~m} ; \\
\text { Group } 4 \\
(\mathrm{n}=36)\end{array}$ \\
\hline \multicolumn{6}{|l|}{ Peripheral muscle force } \\
\hline$\Delta \mathrm{QF}(\mathrm{Nm})$ & $10(0-22)^{*}$ & $\mathrm{II}(0-2 \mathrm{I})^{*}$ & $7(-2-2 I)^{*}$ & $15(4-29)^{*, \neq}$ & $7(-2-15)^{*}$ \\
\hline$\Delta \mathrm{QF}$ (\% from baseline) & $10(0-25)^{*}$ & $8(0-20) *$ & $5(-2-2 I)^{*}$ & $16(6-46)^{*, \neq}$ & II $(-2-24)^{*}$ \\
\hline \multicolumn{6}{|l|}{ Exercise capacity } \\
\hline$\Delta$ Oxygen uptake (\% from baseline) & $8(-5-2 I)^{*}$ & II $(-4-24)^{*}$ & $2(-6-16)^{*}$ & $14(0-24)^{*, \neq}$ & $-4(-17-0)^{*,+, \S}$ \\
\hline$\Delta$ Max workload (\% from baseline) & $14(0-30)^{*}$ & $16(0-28)^{*, \S}$ & $\mathrm{II}(0-2 \mathrm{I})^{*}$ & $22(0-50)^{*,+\neq}$ & $0(0-25)^{+, \S}$ \\
\hline$\triangle 6 M W D(m)$ & $43(12-78)^{*}$ & $59(45-91)^{*}$ & $0(-26-17)^{\dagger}$ & $86(54-136)^{*,+, \neq}$ & $-8(-62-18) *+, \S$ \\
\hline$\triangle 6 M W D$ (\% from baseline) & $10(3-23)^{*}$ & $13(9-2 \mid)^{*}$ & $0(-5-3)^{\dagger}$ & $39(23-67)^{*,+, \neq}$ & $-3(-24-6)^{*+,+\S}$ \\
\hline \multicolumn{6}{|l|}{ Health-related quality of life } \\
\hline$\triangle C R D Q$ dyspnea & $5(2-8)^{*}$ & $6(3-9)^{*}$ & $3(1-8)^{*, \dagger}$ & $6(2-8)^{*}$ & $3(0-6)^{*,+, \S}$ \\
\hline$\triangle$ CRDQ total score & $15(8-24)^{*}$ & $17(||-25)^{*}$ & $12(4-22)^{*, \dagger}$ & $16(\mid 1-24)^{*}$ & $13(2-22)^{*}$ \\
\hline
\end{tabular}

Notes: Data shown as median (IQR). Data was only analyzed for subjects with data at both baseline and 3 months. Group I: $6 \mathrm{MWDi} \geq 350 \mathrm{~m}$ and $\triangle 6 \mathrm{MWD} \geq 30 \mathrm{~m}$; Group 2: $6 \mathrm{MWDi} \geq 350 \mathrm{~m}$ and $\triangle 6 \mathrm{MWD}<30 \mathrm{~m}$; Group 3: 6MWDi $<350 \mathrm{~m}$ and $\triangle 6 \mathrm{MWD} \geq 30 \mathrm{~m}$; and Group 4: 6MWDi $<350 \mathrm{~m}$ and $\triangle 6 \mathrm{MWD}<30 \mathrm{~m}$. $* P<0.05$ for changes from baseline. †Post hoc test versus I; †post hoc test versus 2 ; ${ }^{\text {p}}$ post hoc test versus 3 .

Abbreviations: $\Delta$, difference (3 months - baseline); 6MWD, 6-minute walk distance; 6MWDi, initial 6MWD; CRDQ, chronic respiratory disease questionnaire; IQR, interquartile range; max, maximum; QF, quadriceps force.

\section{Discussion}

The present study confirms the importance of 6MWD as a prognostic indicator of mortality risk in patients with COPD and adds that patients who fail to improve at least $30 \mathrm{~m}$ in $6 \mathrm{MWD}$, as well as those with worse rehabilitation outcomes, have less chances of surviving a 5-year follow-up period. This supports an increasing body of evidence relating 6MWD to mortality across a range of chronic respiratory conditions. ${ }^{3,26-28}$ The present study demonstrated that both

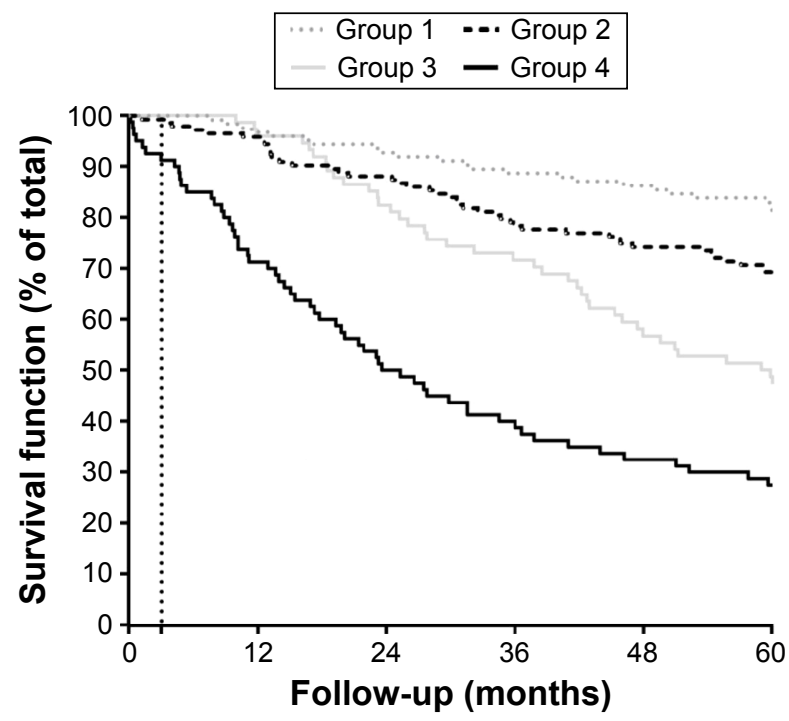

Figure 2 Kaplan-Meier mortality curves for Groups 1-4.

Notes: Group I: $6 \mathrm{MWDi} \geq 350 \mathrm{~m}$ and $\triangle 6 \mathrm{MWD} \geq 30 \mathrm{~m}$; Group 2: 6MWDi $\geq 350 \mathrm{~m}$ and $\triangle 6 \mathrm{MWD}<30 \mathrm{~m}$; Group 3: 6MWDi $<350 \mathrm{~m}$ and $\triangle 6 \mathrm{MWD} \geq 30 \mathrm{~m}$; and Group 4: $6 \mathrm{MWDi}<350 \mathrm{~m}$ and $\triangle 6 \mathrm{MWD}<30 \mathrm{~m}$.

Abbreviations: 6MWD, 6-minute walk distance; 6MWDi, initial 6MWD. the initial distance walked and the magnitude of its improvement with PR were associated with survival. In patients who presented with increased risk of premature mortality due to greater impairment of functional exercise performance (6MWDi $<350 \mathrm{~m}$ ), positive training response (improvement of 6MWD of at least $30 \mathrm{~m}$ ) was associated with better likelihood of 5-year survival to nearly twice as high.

The multivariate regression model, adjusted for confounders, estimated that $6 \mathrm{MWD}>350 \mathrm{~m}$ was associated with lower risk of mortality ( $\mathrm{HR}=0.39$ ) than a lower 6MWD (Table 3 ). This finding is similar to the previous findings by Casanova et al who demonstrated that $350 \mathrm{~m}$ can provide the best sensitivity and specificity of estimated mortality compared to both lower and higher values than this. ${ }^{3}$ Recently, an official systematic review by the European Respiratory Society and the American Thoracic Society on field tests proposed $317 \mathrm{~m}$ as a value discriminating high/low risk of mortality in patients with COPD. ${ }^{2}$ This threshold, despite being based on a large number of investigations, was not validated. The $350 \mathrm{~m}$ threshold was chosen, a priori, as it is used in the multidimensional body mass index, airflow obstruction, dyspnea, and exercise index, where any distance $<350 \mathrm{~m}$ increases mortality risk by a clinically significant margin. ${ }^{26}$

Importantly, it was identified that improved 6MWD with PR was associated with a significant reduction in mortality in a large set of patients referred to PR. This finding has high relevance for clinical practice, as a previous study reported effects of worse prognosis with deterioration of 6MWD. ${ }^{11,29}$ Evidence from a previous study described the effect of PR 
Table 3 Mortality risks estimates using univariate and multivariate regression analysis on possible mortality confounders

\begin{tabular}{|c|c|c|c|c|}
\hline Confounders & $\begin{array}{l}\text { Univariate analysis; } \\
\text { HR }(95 \% \mathrm{Cl})\end{array}$ & $P$-value & $\begin{array}{l}\text { Multivariate analysis; } \\
\text { adjusted } \mathrm{HR}(95 \% \mathrm{CI})\end{array}$ & $P$-value \\
\hline $\mathrm{BMI}<2 \mathrm{l} \mathrm{kg} \cdot \mathrm{m}^{-2}$ & $1.36(1.02-1.80)$ & 0.0327 & - & - \\
\hline Presence of two or more comorbidities & $1.24(1.05-1.47)$ & 0.0114 & - & - \\
\hline Age (per 5 years of increase) & $1.16(1.07-1.25)$ & 0.0001 & $1.18(1.06-1.31)$ & 0.0017 \\
\hline Quadriceps force, as function of weight (per 10 units of increase) & $0.97(0.94-0.99)$ & 0.0217 & - & - \\
\hline $\mathrm{FEV}_{1}, \%$ predicted (per 10 units of increase) & $0.82(0.75-0.89)$ & $<0.0001$ & - & - \\
\hline Oxygen uptake, $\%$ predicted (per 10 units of increase) & $0.79(0.73-0.85)$ & $<0.0001$ & $0.80(0.72-0.89)$ & 0.0010 \\
\hline $\mathrm{DL}_{\mathrm{co}}, \%$ predicted (per 10 units of increase) & $0.78(0.71-0.85)$ & $<0.0001$ & - & - \\
\hline Change in $\mathrm{FEV}_{1}, \%$ predicted after training (per unit of increase) & $0.98(0.96-0.99)$ & 0.0080 & $0.98(0.96-0.99)$ & 0.0258 \\
\hline Change in quadriceps force after training (per 10 units of increase) & $0.90(0.84-0.98)$ & 0.0139 & $0.90(0.82-0.99)$ & 0.0326 \\
\hline Change in BMI after training, per unit of increase & $0.88(0.78-0.99)$ & 0.0391 & - & - \\
\hline $\begin{array}{l}\text { Change in oxygen uptake, \% predicted after training } \\
\text { (per } 10 \text { units of increase) }\end{array}$ & $0.85(0.76-0.94)$ & 0.0026 & $0.83(0.70-0.98)$ & $<0.0001$ \\
\hline Change in $\mathrm{W}_{\max }$ after training (per 10 units of increase) & $0.79(0.70-0.88)$ & $<0.0001$ & - & - \\
\hline Change in $6 \mathrm{MWD} \geq 30 \mathrm{~m}$ & $0.66(0.51-0.85)$ & 0.0013 & $0.68(0.49-0.94)$ & 0.0214 \\
\hline Enrolling in the maintenance program (months 3-6) & $0.62(0.44-0.86)$ & 0.0052 & - & - \\
\hline Initial 6 MWD $\geq 350 \mathrm{~m}$ & $0.39(0.30-0.50)$ & $<0.0001$ & $0.46(0.32-0.65)$ & $<0.0001$ \\
\hline
\end{tabular}

Notes: Only variables that remained in the model are reported in the multivariate regression analysis. Bold font denotes statistical significance $(P<0.05)$. , indicates that the variable was not included in the multivariate model.

Abbreviations: 6MWD, 6-minute walk distance; $\mathrm{BMI}$, body mass index; $\mathrm{Cl}$, confidence interval; $\mathrm{DL}_{\mathrm{co}}$, diffusion capacity for carbon monoxide; $\mathrm{FEV}$, forced expiratory volume in the first second; $\mathrm{HR}$, hazard ratio; $W_{\max }$, maximal workload during cycling exercise test.

on the body mass index, airflow obstruction, dyspnea, and exercise index and its associated positive impact on mortality. The present study showed that patients with stable moderateto-very severe disease who did not have positive outcomes with PR, applied in the usual clinical context (as part of evidence-based COPD management), increased their risk of premature death. Combination of 6MWDi and its changes revealed that such effect on mortality was more pronounced in the severely deconditioned patients (Groups 3 and 4).

The mortality effects observed at 60 months may be influenced by some other factors. The analyses identified several general and disease-related factors known to confound mortality estimates, such as body mass index, lung function, muscle force, and comorbidities. Of note, $21 \%$ of the patients referred to training did not complete the intervention. Although the sensitivity analysis excluding these patients from the model confirmed the lack of effect

Table 4 Mortality risk estimates in the four groups adjusted by confounders

\begin{tabular}{lll}
\hline Adjusted risk compared to G I & HR adjusted $(\mathbf{9 5 \%} \mathbf{C I})$ & P-value \\
\hline G4: $<350 \mathrm{~m}$ and delta $<30 \mathrm{~m}$ & $3.28(2.02-5.33)$ & $<\mathbf{0 . 0 0 0 ~ I}$ \\
G3: $<350 \mathrm{~m}$ and delta $\geq 30 \mathrm{~m}$ & $\mathrm{I} .90(1.28-2.84)$ & $\mathbf{0 . 0 0 1 6}$ \\
G2: $\geq 350 \mathrm{~m}$ and delta $<30 \mathrm{~m}$ & $\mathrm{I} .36(0.92-2.00)$ & 0.1144 \\
\hline
\end{tabular}

Notes: GI, Group I: $6 \mathrm{MWDi} \geq 350 \mathrm{~m}$ and $\triangle 6 \mathrm{MWD} \geq 30 \mathrm{~m}$; G2, Group 2: $6 \mathrm{MWDi} \geq 350 \mathrm{~m}$ and $\triangle 6 \mathrm{MWD}<30 \mathrm{~m} ; \mathrm{G} 3$, Group 3: $6 \mathrm{MWDi}<350 \mathrm{~m}$ and $\triangle 6 \mathrm{MWD} \geq 30 \mathrm{~m} ; \mathrm{G} 4$, Group $4: 6 \mathrm{MWDi}<350 \mathrm{~m}$ and $\triangle 6 \mathrm{MWD}<30 \mathrm{~m}$. Bold font denotes statistical significance $(P<0.05)$.

Abbreviations: 6MWD, 6-minute walk distance; 6MWDi, initial 6MWD; $\mathrm{Cl}$, confidence interval; HR, hazard ratio. on mortality, it is possible that personal characteristics such as motivation to adhere to training play a role on survival. Although 6MWDi and changes in 6MWD were identified as strong independent predictors of mortality, the precise extent of causality cannot be confirmed. Furthermore, other exercise responses to the training were found to be related to mortality in the present cohort (Table 3 ). The observed improvements in oxygen uptake and quadriceps force are directly related to survival effects and reinforce the importance of monitoring responses after PR programs.

The Kaplan-Meier survival curves (Figure 2) revealed additional clinically important information regarding the sustained impact of PR on 6MWD change and potency of PR as a stimulus upon which to guide clinical decisions regarding prognosis and patient care. In patients with considerable impairment of exercise performance (Groups 3 and 4), responses $\geq 30 \mathrm{~m}$ (Group 3) moderate survival trajectory during the subsequent year to levels that are almost identical to those in Groups 1 and 2 (6MWDi $\geq 350 \mathrm{~m}$ ), before resuming a path closer to those in Group 4. The sensitivity analysis confirmed the effect observed in Groups 1 and 3 was not influenced by the potential negative effect of including patients who dropped out in Groups 2 and 4. Therefore, it is important that patients with profound functional limitation (Groups 3 and 4; 6MWDi $<350 \mathrm{~m}$ ) are not discouraged from attending PR. In contrast, this patient subgroup could be considered an important group to be referred to PR programs as the potential benefits of improving functional capacity with rehabilitation are high. 


\section{Limitations}

The findings from this study should be considered in light of some possible limitations. The primary end point of this study (mortality) was verified by using a comprehensive and trustworthy database including patients' medical history. When not available, the end point was searched on electronic obituaries or was obtained by contacting the patients' general practitioners or relatives (increasing the chance of incorrectly retrieved date of death). Although such sources of information can provide bias to the study, the authors excluded any doubtful survival status (only $5 \%$ of the sample). This approach, although limited, guaranteed the reliability of the presented results. This was a retrospective and observational study, and the results related to the $\triangle 6 \mathrm{MWD}$ have not been prospectively confirmed with comprehensive monitoring of other factors that may affect mortality during follow-up. For example, it could be speculated that patients who are able to sustain improvements in exercise capacity for longer periods may have decreased mortality risks during follow-up. This could not be confirmed due to incomplete availability of 6MWD data in the yearly follow-up visits. Furthermore, frequency of exacerbations (hospitalized or nonhospitalized), changes to medications and comorbidities could all contribute to long-term outcomes. Although best attempts were made to control for as many potentially influential factors as possible in the present analysis, this was limited to data available within existing comprehensive databases. Data regarding the incidence of the first respiratory-related hospitalization, for example, were only accurately determined during the first year after beginning PR and did not distinguish between frequent and infrequent exacerbator phenotypes. Nevertheless, it is important to note the association of lack of improved 6MWD with worse survival in both functional exercise capacity classes (Groups 2 and 4). Identification of the precise mechanism(s) driving the interaction between lack of physiologic training response and decreased survival should be a priority of future investigations in this field.

\section{Conclusion}

The findings from this present study confirm the prognostic importance of the 6MWT in patients with stable COPD. Both poor 6MWD and lack of its improvement with $\mathrm{PR}(<30 \mathrm{~m})$ were independently related to worse 5 -year survival in patients with COPD referred to PR.

\section{Acknowledgments}

The authors would like to thank Matthias Loeckx for his scientific input provided to the present manuscript.
We would also like to thank physiotherapists Ilse Muylaert, Iris Coosemans, Veronica Barbier, and the staff of the Respiratory Rehabilitation Department and Pulmonary Function Department at the University Hospital Leuven for their assistance to collect data and conduct exercise training. We are also grateful to Doctor Hans Scheers for statistical advice provided for this manuscript. CAC is a $\mathrm{PhD}$ fellow of CNPq/Brazil (202425/2011-8); DL is a postdoc fellow of Flemish Research Foundation; $\mathrm{CO}$ is a recipient of a European Respiratory Society Fellowship (LTRF 2014-3132); TT is supported by Flemish Research Foundation (FWO \#G.0871.13); and HD is the recipient of a joint ERS/SEPAR Fellowship (LTRF 2015).

\section{Disclosure}

The authors report no conflicts of interest in this work.

\section{References}

1. Holland AE, Spruit MA, Troosters T, et al. An official European Respiratory Society/American Thoracic Society technical standard: field walking tests in chronic respiratory disease. Eur Respir J. 2014;44(6): 1428-1446.

2. Singh SJ, Puhan MA, Andrianopoulos V, et al. An official systematic review of the European Respiratory Society/American Thoracic Society: measurement properties of field walking tests in chronic respiratory disease. Eur Respir J. 2014;44(6):1447-1478.

3. Casanova C, Cote C, Marin JM, et al. Distance and oxygen desaturation during the 6-min walk test as predictors of long-term mortality in patients with COPD. Chest. 2008;134(4):746-752.

4. Gerardi DA, Lovett L, Benoit-Connors ML, Reardon JZ, ZuWallack RL. Variables related to increased mortality following out-patient pulmonary rehabilitation. Eur Respir J. 1996;9(3):431-435.

5. Vanhees L, Fagard R, Thijs L, Amery A. Prognostic value of traininginduced change in peak exercise capacity in patients with myocardial infarcts and patients with coronary bypass surgery. Am J Cardiol. 1995; 76(14):1014-1019.

6. Spruit MA, Singh SJ, Garvey C, et al. An official American Thoracic Society/European Respiratory Society statement: key concepts and advances in pulmonary rehabilitation. Am J Respir Crit Care Med. 2013 188(8):e13-e64

7. Puhan MA, Gimeno-Santos E, Scharplatz M, Troosters T, Walters EH, Steurer J. Pulmonary rehabilitation following exacerbations of chronic obstructive pulmonary disease. Cochrane Database Syst Rev. 2011;(10):CD005305.

8. Cote CG, Celli BR. Pulmonary rehabilitation and the BODE index in COPD. Eur Respir J. 2005;26(4):630-636.

9. McCarthy B, Casey D, Devane D, Murphy K, Murphy E, Lacasse Y. Pulmonary rehabilitation for chronic obstructive pulmonary disease Cochrane Database Syst Rev. 2015;2(2):CD003793.

10. Troosters T, Gosselink R, Decramer M. Exercise training in COPD: how to distinguish responders from nonresponders. J Cardiopulm Rehabil. 2001;21(1):10-17.

11. Polkey MI, Spruit MA, Edwards LD, et al. Six-minute-walk test in chronic obstructive pulmonary disease: minimal clinically important difference for death or hospitalization. Am J Respir Crit Care Med. 2013 187(4):382-386.

12. Vestbo J, Hurd SS, Agusti AG, et al. Global strategy for the diagnosis, management, and prevention of chronic obstructive pulmonary disease: GOLD executive summary. Am J Respir Crit Care Med. 2013;187(4) $347-365$. 
13. Quanjer PH, Tammeling GJ, Cotes JE, Pedersen OF, Peslin R, Yernault JC. Lung volumes and forced ventilatory flows. Report Working Party Standardization of Lung Function Tests, European Community for Steel and Coal. Official Statement of the European Respiratory Society. Eur Respir J Suppl. 1993;16:5-40.

14. Puente-Maestu L, Palange P, Casaburi R, et al. Use of exercise testing in the evaluation of interventional efficacy: an official ERS statement. Eur Respir J. 2016;47(2):429-460.

15. American Thoracic Society; American College of Chest Physicians. ATS/ACCP Statement on cardiopulmonary exercise testing. Am J Respir Crit Care Med. 2003;167(2):211-277.

16. Guyatt GH, Berman LB, Townsend M, Pugsley SO, Chambers LW. A measure of quality of life for clinical trials in chronic lung disease. Thorax. 1987;42(10):773-778.

17. Troosters T, Gosselink R, Decramer M. Short- and long-term effects of outpatient rehabilitation in patients with chronic obstructive pulmonary disease: a randomized trial. Am J Med. 2000;109(3):207-212.

18. Pitta F, Troosters T, Probst VS, Langer D, Decramer M, Gosselink R. Are patients with COPD more active after pulmonary rehabilitation? Chest. 2008;134(2):273-280.

19. Burtin C, Saey D, Saglam M, et al. Effectiveness of exercise training in patients with COPD: the role of muscle fatigue. Eur Respir J. 2012; 40(2):338-344.

20. Marquis K, Debigare R, Lacasse Y, et al. Midthigh muscle crosssectional area is a better predictor of mortality than body mass index in patients with chronic obstructive pulmonary disease. Am J Respir Crit Care Med. 2002;166(6):809-813.
21. Fletcher C, Peto R. The natural history of chronic airflow obstruction. Br Med J. 1977;1(6077):1645-1648.

22. Martinez FJ, Foster G, Curtis JL, et al. Predictors of mortality in patients with emphysema and severe airflow obstruction. Am J Respir Crit Care Med. 2006;173(12):1326-1334.

23. Schols AM, Slangen J, Volovics L, Wouters EF. Weight loss is a reversible factor in the prognosis of chronic obstructive pulmonary disease. Am J Respir Crit Care Med. 1998;157(6 Pt 1):1791-1797.

24. Divo M, Cote C, de Torres JP, et al. Comorbidities and risk of mortality in patients with chronic obstructive pulmonary disease. Am J Respir Crit Care Med. 2012;186(2):155-161.

25. Schunemann HJ, Puhan M, Goldstein R, Jaeschke R, Guyatt GH. Measurement properties and interpretability of the chronic respiratory disease questionnaire (CRQ). COPD. 2005;2(1):81-89.

26. Celli BR, Cote CG, Marin JM, et al. The body-mass index, airflow obstruction, dyspnea, and exercise capacity index in chronic obstructive pulmonary disease. $N$ Engl J Med. 2004;350(10):1005-1012.

27. Miyamoto S, Nagaya N, Satoh T, et al. Clinical correlates and prognostic significance of six-minute walk test in patients with primary pulmonary hypertension. Comparison with cardiopulmonary exercise testing. $\mathrm{Am}$ J Respir Crit Care Med. 2000;161(2 Pt 1):487-492.

28. Eaton T, Young P, Milne D, Wells AU. Six-minute walk, maximal exercise tests: reproducibility in fibrotic interstitial pneumonia. $\mathrm{Am}$ J Respir Crit Care Med. 2005;171(10):1150-1157.

29. Pinto-Plata VM, Cote C, Cabral H, Taylor J, Celli BR. The 6-min walk distance: change over time and value as a predictor of survival in severe COPD. Eur Respir J. 2004;23(1):28-33. 


\section{Supplementary materials Methods}

\section{Statistical analysis}

Statistical analyses were conducted with SAS Version 9.3 (SAS Institute Inc., Cary, NC, USA). Data were described as mean \pm standard deviation or median [interquartile range] according to data distribution. Data normality was assessed by Shapiro-Wilk test.

\section{Data comparisons}

Unpaired $t$-test and Mann-Whitney test were used to compare baseline differences between subjects who did or did not complete the training. One-way analysis of variance and Kruskal-Wallis tests were used to compare differences between the four groups at both baseline and after training.

\section{Survival analysis}

In order to verify survival estimates, a nonparametric survival method was used to plot Kaplan-Meier survival curves. Between-group differences were analyzed by using $\log$ rank test.

Cox regression analysis was used to adjust mortality estimates for potential confounders (eg, age, quadriceps force, ${ }^{1}$ lung function, ${ }^{2}$ maximal exercise capacity, ${ }^{3}$ body mass index,${ }^{4}$ and comorbidities ${ }^{5}$ ). Additional impact on mortality by improving other training outcomes (ie, cycling exercise test, quadriceps force, health-related quality of life, and body mass index) was also investigated. Univariate regression analysis was used to identify the significance of aforementioned confounders. Statistically significant variables were added into a multivariate model. Individually adjusted risks of mortality were estimated by calculating hazard ratios.

\section{Sensitivity analysis on mortality estimates}

In order to assure that no factors related to the group allocation criteria or the long-term inclusion would interfere on the mortality estimates, two sensitivity analyses were conducted.

1. Removing "dropout" subjects from Groups 2 and 4. Patients who failed to complete the 3 months of exercise training were considered "drop-out" and were allocated into either the Group 2 (if initial values of $6 \mathrm{MWD} \geq 350 \mathrm{~m}$ ) or Group 4 (if initial values of 6MWD $<350 \mathrm{~m}$ ).

2. Comparing mortality estimates between subjects referred to PR program in the first and the second half of the 11 years of inclusion (1999-2010). In order to guarantee that possible differences in medical treatment during the entire follow-up would not interfere in the survival estimates, survival estimates between patients referred to the rehabilitation program between January 1999 and July 2004 (first half) and those referred between August 2004 and July 2010 (second half) were compared.

\section{References}

1. Marquis K, Debigare R, Lacasse Y, et al. Midthigh muscle cross-sectional area is a better predictor of mortality than body mass index in patients with chronic obstructive pulmonary disease. Am J Respir Crit Care Med. 2002;166(6):809-813.

2. Fletcher C, Peto R. The natural history of chronic airflow obstruction. BMJ. 1977;1:1645-1648.

3. Martinez FJ, Foster G, Curtis JL, et al. Predictors of mortality in patients with emphysema and severe airflow obstruction. Am J Respir Crit Care Med. 2006;173(12):1326-1334.

4. Schols AM, Slangen J, Volovics L, Wouters EF. Weight loss is a reversible factor in the prognosis of chronic obstructive pulmonary disease. Am J Respir Crit Care Med. 1998;157(6 Pt 1):1791-1797.

5. Divo M, Cote C, de Torres JP, et al. Comorbidities and risk of mortality in patients with chronic obstructive pulmonary disease. Am J Respir Crit Care Med. 2012;186(2):155-161.

\section{Publish your work in this journal}

The International Journal of COPD is an international, peer-reviewed journal of therapeutics and pharmacology focusing on concise rapid reporting of clinical studies and reviews in COPD. Special focus is given to the pathophysiological processes underlying the disease, intervention programs, patient focused education, and self management protocols.

\section{Dovepress}

This journal is indexed on PubMed Central, MedLine and CAS. The manuscript management system is completely online and includes a very quick and fair peer-review system, which is all easy to use. Visit $\mathrm{http}: / / \mathrm{www}$.dovepress.com/testimonials.php to read real quotes from published authors. 